\title{
Orsolya Kolozsvari
}

College of Coastal Georgia, U.S.A.

\section{"Physically We Are Apart, Mentally We Are Not."} Creating a Shared Space and a Sense of Belonging in Long-Distance Relationships

DOI: https://doi.org/10.18778/1733-8077.11.4.05

Abstract As couples tend to be referred to as "being together," long-distance partners, who spend most of their time apart and in different spaces, might face a challenge delineating and validating their relationship Through in-depth interviews with 20 couples in a long-distance relationship, this study explores how long-distance partners linguistically and symbolically mark the boundaries of their relationship, and also transcend any real or perceived gaps between distance and closeness in the process. While they rarely shared a physical space, my participants created joint socio-mental spaces, which enhanced their sense of belonging and helped to expand definitions of intimacy and space.

Keywords Long-Distance Relationships; Boundary Placement; Boundary Transcendence; Space; Grounded Theory Methods; Symbolic Interactionism

arking the boundaries of being a couple and sharing a home or other space are essential ways of symbolically creating and maintaining a sense of belonging and intimacy between romantic partners. When couples are in a long-distance relationship, especially if they have met online and not yet in person, and where they rarely share

Orsolya Kolozsvari is an Assistant Professor of Sociology at the College of Coastal Georgia (Brunswick, GA, United States). Her main areas of interest and research include long-distance relationships and marriages, transnational and inter-ethnic families, gender and sexuality, immigration, ethnicity, and cognitive sociology

email address: okolozsvari@ccga.edu a physical space or a home, it is intriguing to examine how they still establish boundaries of being a couple and a sense of shared space and belonging. Through in-depth interviews, this study explores how 20 heterosexual couples in a long-distance relationship (40 individuals total) accomplish such goals.

Couples in long-distance relationships often deviate from spatial and socio-temporal norms, that is, social expectations regarding the use of space and time (Zerubavel 1981). First, for parts of the relationship they occupy different spaces, which violates preconceived notions about couples in romantic relationships where spatial closeness is assumed. Couples are often defined by "being together" (both in a temporal and spatial sense), and long-distance couples contradict this definition by spending at least some of their time apart and in separate spaces. This situation provides an intriguing opportunity to study how people create a sense of togetherness, transcend perceived boundaries between being together and apart, close and far away, and mark their own space, which, in the case of long-distance partners, might be a space that only exists in their cognitive realm (or in cyberspace).

In defining themselves as a couple, long-distance partners draw a boundary that separates them as a couple from the rest of the world. As Zerubavel (1991:2) put it, "[t]o define something is to mark its boundaries, to surround it with a mental fence that separates it from everything else." Geographically close couples mark their own boundaries and create their own reality (Berger and Kellner 1964; Vaughan 1986; Richardson 1988); however, this boundary work is even more strenuous for long-distance partners because their relationship is less socially legitimated. Just the phrase "long-distance relationship" socially marks the relationship and differentiates it from "regular" relationships that are assumed to be geographically close. The social marking of a category exaggerates the contrast between the marked and unmarked category (thus creating a boundary between them), naturalizes the unmarked, and paints a marked category as distinct and potentially more problematic than the unmarked (Brekhus 1996). I examined what language and symbols were used to mark the boundaries of togetherness for long-distance couples.

Social constructionism and symbolic interactionism have served as the major theoretical backgrounds for this study. I have relied on social constructionism in exploring how long-distance couples created their own reality, their own definition of couplehood and shared space (Berger and Kellner 1964; Berger and Luckmann 1966). As the social construction of reality tends to occur through the use of language (Berger and Kellner 1964; Berger and Luckmann 1966; Vaughan 1986), the examination of the language and words long-distance couples used in their accounts shed light on how they constructed meaning.

A symbolic interactionist approach has also played an essential role in this study. As Blumer (1969) contended, symbolic interactionism rests on three main premises: humans act towards things based on the meanings those things have for them; meanings are created through social interaction; and meanings are understood and transformed through an interpretative process. I explored what a relationship, especially a long-distance relationship (LDR), meant for long-distance couples. Also, I endeavored to learn how long-distance couples created these meanings and definitions together, through interacting with each other. Finally, my goal was to discover, through in-depth interviewing and focusing on language use, how long-distance couples interpreted and negotiated their meanings of a geographically long-distance versus close-distance relationship, as well as belonging and a shared space.

\section{Data and Methods}

This study included a non-random sample of 20 heterosexual couples in a long-distance romantic relationship, a total of 40 respondents. By a long-distance 
romantic relationship I mean a romantic involvement where the partners maintain separate residences, live at least 100 miles apart, and meet face-to-face no more than once every week. Some studies define LDRs by physical distance only (Lyndon, Pierce, and O'Regan 1997; Knox et al. 2002; Johnson et al. 2007; 2008), but I decided against that because couples with an abundance of resources and free time are likely to be able to meet more often even if they are far away, while couples with more limited resources might see each other less frequently even if the distance between them is not vast. My definition approximates those most frequently used in LDR research, where LDRs are described as relationships where it is difficult or even impossible for the partners to see each other on a daily or even weekly basis (Gerstel and Gross 1984; Guldner and Swensen 1995; Guldner 1996; Dainton and Aylor 2001; Maguire 2007; Stafford and Merolla 2007; Hill et al. 2009; Maguire and Kinney 2010), but takes it one step further by focusing both on frequency of contact and distance.

The goals of this study determined my sampling strategy. Accordingly, I conducted purposive, selective sampling. Purposive (selective) sampling means that participants or cases are selected non-randomly, based on some criteria that are determined in advance, before the data collection starts (Malterud 2001; Guest, Bunce, and Johnson 2006; Draucker et al. 2007). Within selective sampling, I mostly relied on criterion sampling, which stands for selecting cases based on certain predetermined criteria that are key in my study (Draucker et al. 2007). The major advantage of using a selective sampling strategy was that I could ensure that all the selected cases match the criteria I was looking for (marital status, country of residence, nationality, past or present LDR).

Driven by theoretical considerations, I purposely divided the sample by marital status, country of residence, nationality, and past versus current LDR status. I wanted to explore how these factors might influence how couples create and negotiate a sense of belonging and space. This resulted in four subcategories: five married couples, where both partners lived in the United States and were Americans; five couples who had had an LDR with each other in the past, but had closed the distance, and were now married to one another; five unmarried couples in a current LDR, where both partners lived in the United States and were Americans; five unmarried couples where one partner lived in the United States and the other lived in another country, and each was a different nationality.

As I was interviewing people in LDRs, some respondents lived far away, even in a different country, and limited financial resources did not allow me to interview everyone face-to-face. In addition, time constraints prevented me from waiting until both respondents were in the same town to be able to interview them both in person. Therefore, I interviewed some respondents through Skype, and others by telephone, depending on whether a respondent had a Skype account or simply preferred the phone. The interviews were conducted between September 2011 and February 2012. Each partner in a couple was interviewed separately.

In my analysis, I used grounded theory methods and relied on its three stages: open, axial, and se- lective coding. I developed concepts early on during open coding and employed a concept-indicator model (Glaser 1978; Strauss 1987; LaRossa 2005). By an indicator I mean a piece of text (a letter, a word, a sentence, a paragraph, etc.) deemed significant in the analysis, and by a concept I mean a label that I associate with one or more indicators (Glaser 1978; Strauss 1987; LaRossa 2005). My goal was to begin employing constant comparisons to the text early; that is, when I was coding an indicator for a concept, I was comparing that particular indicator with other indicators that I had already coded the same way (Glaser 1978; Strauss 1987; LaRossa 2005). After open coding, the next stage was axial coding. Axial coding stands for developing hypotheses about the relationships between variables (Strauss 1987; LaRossa 2005). Coding for processes and coding for strategies are also parts of axial coding (LaRossa 2005). Therefore, I paid attention to these in my analysis.

Finally, after open and axial coding, selective coding is the final phase of a grounded theory analysis. Selective coding involves the selection of a core variable, which is a variable that is theoretically saturated (probably the most saturated of all variables in a study), has the most connections to other variables, and is central to the main story (Glaser 1978; Strauss 1987; LaRossa 2005). The core variable in this study was the "extent of boundary transcendence." It was highly saturated, and it appeared the most frequently in the data. Boundary transcendence stands for bridging the gap between two separate realms or categories and integrating them instead of separating them (Nippert-Eng 1996). The dimensions of this variable were "rigid boundary placement" (drawing a sharp line between two catego- ries), "some boundary placement," "some boundary transcendence," and a "high level of boundary transcendence."

Results

\section{Defining and Marking the Boundaries}

\section{of Togetherness}

The beginning and end of relationships may be somewhat blurry, involving a gradual transition, or there might be a sharp distinction between being in a relationship versus not. First, I examine how my participants drew a line between being single and being a member of a couple, which can illuminate how couples are initially formed, and what separates them from singles. It was rare among my respondents to describe the transition into couplehood as something fluid and almost imperceptible, but this was not completely absent from my data. For example, Tim could not pinpoint a date or event when he and his now-wife became a couple. As he put it, "It's not like black and white, it's more like gradual. You keep on meeting, then one thing leads to another." Interestingly, Tim's wife, Julianna, linked the beginning of their relationship more to a date and event than Tim did. As she explained it,

The first date was more like we didn't talk about it, but we held hands and kissed ... But, we didn't talk like, "OK, now we're a couple." The second date was when we were like, "OK, maybe we're more than just friends."

Her comment underscores the importance of two people deciding and agreeing that they are establishing a couple and becoming a "we." 
Unlike Tim, and similar to Julianna, nearly all of my participants drew a boundary between being in a relationship versus not, and this was negotiated by the partners, and very frequently temporally signified, as well. Most of them identified a date when they became a couple. As Ben shared with me, "On [a specific date] I asked her, I said, 'Would you like to be my girlfriend?"' His girlfriend, Sarah, had a similar recollection: "He asked me to be his girlfriend ... We said 'I love you' to each other on [a specific date]. We didn't officially become a quote-unquote couple, we didn't officially give it a name until [two weeks later]." Lindsey and her boyfriend, Daniel, did not view themselves as a couple right away after they had met online, either, but a few weeks later they began to do so. As Lindsey described it, "[On a specific date] we actually officially announced we're a couple, and we really want to be together." The couples now considered these dates their anniversaries.

The accounts above illustrate that there is often a rigid boundary between singlehood and couplehood, and partners construct this boundary together by boundary placement. Boundary placement "visibly draws the line between [physical and mental] realms" (Nippert-Eng 1996:8). Placing boundaries together indicates that the construction of boundaries for couples that separate them from the rest of the world is also about creating solidarity, strengthening ties, and social cohesion between the partners in their formation of a dyadic group.

By marking the boundaries of couplehood together, long-distance partners also transcend any perceived boundaries between closeness and distance. At the same time, this is not necessarily a very private moment. Lindsey referred to announcing it to the world that they were a couple. As Vaughan (1986:40) elucidated, "When we couple, we act in ways that publicly link us with the other person." This is what Lindsey and her partner, as well as others among my participants, were doing. Marking the beginning of a relationship and its separation from not being in a relationship can be ritualized (Zerubavel 1979; Vaughan 1986; Richardson 1988), and this was manifested in my interviewees privately discussing and publicly announcing their belonging to each other. The "mental fences" around a new relationship were often also crafted by words that my participants, and most people in society in general attribute significant meanings to, such as "couple," "boyfriend," and "girlfriend."

Lindsey and Daniel, as well as Ben and Sarah, did not start considering themselves a couple from their first date or the first day they met; they did so a few weeks later. In some cases, the moment of becoming a couple came later. Heather and her partner had casually dated in an LDR for years before they decided to become a couple. As she explained it, "On the anniversary we met he asked me to be his girlfriend." Similar to Heather and her boyfriend, in most cases, when the relationship was not viewed as official righ away or shortly after the first meeting or date, the men initiated marking the boundaries of the relationship by making it official. Allison and her boyfriend were an exception. They had casually dated for about a year before Allison prompted a change to set up the boundaries of their relationship. She asserted, "I told him 'You gotta decide if you're gonna stay here or not. If you're gonna go, that's cool, but you gotta go now.' So from that point on we've sort of been on."
My respondents were not only using monogamy to draw a rigid boundary around their relationship, but they were also firm on defining that they had a relationship, even if they had never met face-toface. Lucy, for instance, had not met Keith in person when I interviewed her. Still, she had no problem mapping out the boundaries of their romantic relationship. When she referred to dating Keith and being in a relationship, I asked her how it was different from a close friendship. She replied,

Different from a close friendship because I have friends that are male, and I just wouldn't talk to them the way I talk to him, you know, the little "I love yous," or "wish you were here," and things like that.

For her, emotional intimacy, their mutual understanding that they had a romantic relationship, and their romantically charged language use separated it from a friendship. Her partner, Keith, felt the same way: "We just mutually started to, you know, have mutual feelings for each other. That's when we became a couple ... I guess you just have deeper feelings for that person than in a friendship." Chloe had not met her partner, Bryce, either, but still asserted, “We're a couple. We haven't met yet, but we're completely for each other." By confirming that they were in a relationship, Lucy and Chloe engaged in boundary placement, drawing a line between two realms considered separate (Nippert-Eng 1996), and also transcended boundaries by establishing and maintaining a relationship without any face-to-face interaction, thus challenging taken-for-granted assumptions about the necessity of face-to-face encounters in creating intimacy (Stafford 2005)
Emotional commitment was one of the major factors in charting the boundaries of a relationship Emotional and mental bonds and a decision to be together solidified couplehood for my respondents. As Lindsey put it, "You can be together even if it's, if he's 9,000 miles away because it's this emotional bond you carry." Allison agreed, "I still define us being together even though we're not in the same city. So for me not being together in this relationship was when the emotional commitment was not there." For her, emotional closeness and commitment determined that they were in a relationship. Felix Heather's partner, conceded, "There's the mental being together ... that you have someone you love, and there is passion, and all of that comes from that one person." Hank mentioned the mental aspect of being together, as well, "Physically we're apart, mentally we're not." He seemed to place a boundary between physical togetherness and being apart, but cognitively transcended any boundaries between emotional closeness and distance. In his study of online relationships, Ben-Ze'ev (2004:53) called the phenomenon of being physically distant but emotionally close "detached attachment." Detached attachment characterizes all committed long-distance couples, not only the ones who maintain a relationship online.

Physical proximity did not increase my respondents' sense of being part of a couple. When I asked Daniel, for example, whether his definition of him and Lindsey as a couple varied when in the same space versus apart, he insisted: “It doesn't matter. We are a couple, no matter what." Roy concurred, “The definition of being a couple doesn't really change being together or apart." These examples 
suggest that distance and closeness are not necessarily opposites, or at least that the boundaries between them can be permeable in LDRs.

Language use can also contribute to blurring boundaries between perceived or real togetherness and distance, as well as between geographically long-distance and close-distance relationships. Some of my respondents resisted defining their relationships as LDRs because they did not want to view them as different from any other relationship, or feel that closeness might be compromised in an LDR. As Gabriel put it, "I don't even wanna call it an LDR, but it is. Every time I hear about someone who is in an LDR, I'm like, 'Get a life,' you know. I don't wanna think I'm in it." Gabriel might have preferred not to use the term LDR for his relationship because he attached negative connotations to the term, and he did not want his relationship to be seen as inferior to any other relationship. His girlfriend, Jamie, was reluctant to label their relationship an LDR, as well: "I guess it would be considered long-distance, but it doesn't really feel like long distance." Jamie and Gabriel lived on two different continents. Therefore, Jamie was right; from the outside, their relationship would have been considered an LDR

Leah avoided using the term LDR, as well. As she explained it,

I think my definition of LDR is kind of like really long, and you don't see each other frequently, and there's at least a body of water separating you. What we have now, that we can see each other more often ... To me that doesn't even qualify as long distance.
Her frame of reference influenced her definition of an LDR, as well; before marriage she and her now-husband had had a greater distance between them than they did when I interviewed them. As Zerubavel (1991:2) elucidated, "[t]o define something is to mark its boundaries, to surround it with a mental fence that separates it from everything else." Using the term LDR for a relationship might separate it from other relationships and inflate the differences between the two. When we mark a category, we not only differentiate it from other categories, we also make it seem less natural or potentially more problematic than an unmarked category (Brekhus 1996). This might be a reason for evading the term LDR.

When Sandy marked her LDR, for example, she used the term "non-traditional relationship." As she described it, "This is a non-traditional relationship already, so we have to figure out what's our thing, as we say, what's our deal." She was engaging in splitting, that is, emphasizing intergroup differences between long-distance and close-distance relationships (Zerubavel 1991; 1996). Her comment also highlights the agency couples have in creating their own reality and relationship (Berger and Kellner 1964; Vaughan 1986; Richardson 1988).

When pointing out any potential differences between long-distance and close-distance relationships, my participants were more likely to mark non-LDRs than LDRs. Some of the terms they used were value-neutral, such as "close-distance" and "same-city" relationships. These terms can be considered retronyms, that is, new names for concepts to differentiate their original form from newer versions. Before LDRs, or outside of the LDR communi- ty, relationships have just been called relationships, assuming that most of them were geographically close. However, the emergence and proliferation of LDRs have led to creating retronyms for proximal relationships to distinguish them from LDRs. Some of the couples I interviewed used less value-neutral terms for differentiation, such as "normal" or "regular" relationships for geographically close relationships. Such terms inadvertently reinforce the social legitimacy of relationships that are non-LDRs and potentially undermine the value of LDRs and make them appear "abnormal" or "irregular." My respondents never used such terms to describe their own relationship; however, the implication of describing non-LDRs as "normal" or "regular" might be that LDRs are not.

I also found that when my participants differentiated between "normal" relationships and LDRs, they often endeavored to highlight the advantages of LDRs, or why they might be even superior to nonLDRs. For instance, Vanessa contended, "In many ways it's way better than a normal relationship because we don't see each other that much, but when we do, there's something to share. So it's different from a normal relationship. You appreciate the time more." Steven, a man in another couple, agreed,

If you are in a normal relationship in the same town, maybe you're wondering how committed somebody is. We never had those doubts ... You get to know each other on a level that might not happen in a normal relationship.

These justifications seemed to be necessary-as implications of LDRs deviating from the norm de- creased the status of LDRs, justifications of them as higher quality in some way than other relationships elevated their status.

Relationships are not only defined and created by couples themselves, they are also reinforced or challenged by others (Berger and Kellner 1964; Vaughan 1986). Family members and friends are especially influential in marking the boundaries of couplehood. Receiving support from family and friends (or society in general) tends to solidify the boundaries of relationships, whereas questioning the relationship can lead to a couple having to work harder for social legitimacy. Many of my respondents got positive feedback from family and friends, and they recognized the importance of such support. As Daniel described it, “My family is actually supporting us quite nicely ... I really don't think it would be doable if it wasn't at least one set of parents supporting." Zachary had his parents' support, as well: “My family absolutely adores Vanessa. They even said if we break up, they would disown me." Nina had her family behind their relationship, too: "I had a very, very strong support from my father and my sister ... That makes a big difference. You have to have some support." Having parents' blessing was even more important for those of my respondents who were young and were close to their parents.

While many friends were supportive of LDRs, some were not. Paige's comment embodied such an example:

A very close friend had a very hard time dealing with it 'cause she was like, "You can't marry this guy until I meet him." She felt like as a best friend she deserves to get her opinion out there ... I think they just 
thought I was crazy for falling in love with someone over the Internet and going 9,000 miles to see him.

Emilia's sanity was also questioned when she first visited her boyfriend after having met him online:

Everyone said that he would kidnap me, sell me, I would never get home, and how could I be such a fool to trust him, how could I come to stay with a stranger in a foreign country. Most of my friends were against it ... So dealing with people's reactions wasn't easy. If everyone says you're crazy, you either believe it, or you insist that you are right. I insisted that everyone else was wrong, and I was right.

Emilia's use of the word "insist" twice indicates that she had to work hard to assuage everyone's doubts and legitimate her relationship, which was the case with all of those respondents who experienced others challenging their LDR.

Sometimes the whole existence of a relationship was questioned. As Sandy shared with me: "I have a friend who says grown-ups don't have open LDRs. He's like, 'You're not in a relationship.'” Lindsey encountered a lot of resistance, as well: "A lot of people rejected it, my family rejected it a whole lot. They didn't like the idea at all. They think I should see somebody real. Real." Her parents' use of the word "real" suggests that they did not recognize her relationship as legitimate. This happened to a much greater extent to those of my participants who were young, had an online relationship, and/or their partner was in another country, which suggests that these boundaries are seen as especially rigid.

\section{Creating a Shared Space}

Long-distance couples occupy different spaces most of the time, which can reinforce a sense of segmented lives and separateness. All of the couples I interviewed had two separate residences at the time of their LDR. Only four couples had shared a living space before their LDR. Separate living spaces demarcated the line between individual lives and lives together. Several of my respondents mentioned this issue. For example, Todd and April both did. As Todd described it, "I feel like both of us had individual spaces. When I came to [her town], I felt very much like her apartment was her apartment. And the same with my place." April reverberated the same thought: "Back then, when we were living apart, I felt like my apartment was definitely my apartment. It wasn't a shared space. And the same with where he lived."

\section{Steven shared Todd and April's approach:}

Sheila had an apartment in [her town]. I guess that was like always her space. I don't know if we had a joint space. I ended up eventually in a one-bedroom apartment. I'm sure she never felt that was her space ... She had no space to put her stuff.

Steven raised another common issue: not only a sense of feeling that the other person's space was her or his space alone, but also that the visiting person sometimes literally had no room at her or his partner's place. Marissa and Hank used to share a house years ago, but since she had moved, her space in the old house ceased to exist. As Marissa put it,
I know I have no space left in that house. So the first thing I will have to do when I get back is reclaim my space ... I'm gonna have the two spare bedrooms, and those will be mine, and you need to get your butt out of here, big boy.

Hank was aware of occupying Marissa's former space in the house, as well, and also that he would need to work on that before she got back:

She'll eventually come back, and I'll have to move some stuff and clean up some stuff. When you live apart for so long, and you have your own house, the empty spaces kind of get filled up ... I got an office in our house, and when I took some stuff out of the office last time she was here, she was very adamant about me putting it back in the office. She took the box, and put it back in the office. She didn't want it to spread out to other parts of the house. She would be extremely pissed with me 'cause I used an extra room for office, which I will need to clean up before she gets back.

While visiting partners sometimes felt they had no room at their significant other's place, participants whose partners visited occasionally felt that their space was intruded upon. Marissa offered an example for this, too: “My house is very tiny here, it's all I need. And he walks in and fills it. He fills the house." After having lived together with Gary for a while, Allison reclaimed her individual space when she moved: "I like it here because he's a mini hoarder, a packrat. So now I have my space back to myself. That makes me happy that there's not crap everywhere." Allison and Marissa endeavored to place such a sharp boundary between their space and their partner's that they were dreading contamination of their independence and newly gained space and separate sense of self (Zerubavel 1991). Moving Hank's box back to his office can be seen as a mental "rite of separation" (Zerubavel 1991) delineating the line between shared and individual spaces, between "we" and "I." Marissa was so protective of her space that she wanted to preserve it even after moving back home. As she half-jokingly asserted, "I tease him, you know, when I move back to [his town], you're gonna need to get me a house two blocks away."

None of my interviewees felt that they had a permanent shared physical space during their LDR. However, this does not mean that all of them reported the lack of a joint space. This finding deviates from most previous LDR research, where not having a shared house or some other shared physical space was a common complaint (Gerstel and Gross 1984; Winfield 1985; Sahlstein 2004). Several of my respondents contended that they had a space together. Even if in many cases it was not an actual space but rather a non-physical space they created, they still saw it as their own. For some, a joint space was realized through cyberspace. Ben and Sarah were one example. As Ben described it, "I feel like our space is on Skype ... Our space is through whatever Skype uses to connect us, through the Internet." Being on the phone or texting were mentioned as shared space, as well, which underscores the role of modern communication technology in crafting spaces.

Cognitive spaces were also listed as forms of shared space. As Felix explained it, "We have a mental space." Chloe, Bryce's partner, contended, "I feel 
like we have our own little imaginary space." Jamie shared a cognitive space with Gabriel, as well. As she elucidated,

It would be a space in my mind where we're on a page together, and we know that eventually we can move to or see each other. It's just a page in my mind where he would be on the same level as me.

Creating a cognitive shared space or one in cyberspace can be considered acts of boundary transcendence.

Socio-mental spaces, which are created cognitively by at least two individuals in unison, are frequently viewed as purely imaginary, but they can be just as real as physical spaces for the people that "visit" them (Chayko 2002; 2008). Thus, sharing a cognitive, or socio-mental space can be considered not only an act of boundary transcendence between the physical and mental, but also a way to erase the boundary between the two.

Transgressing actual or socially constructed boundaries so seamlessly is "a hallmark of creativity" (Zerubavel 1991:117). Time was also employed to annihilate the boundary between spatial togetherness and separateness, which underscores Nippert-Eng's (1996) point that time is often used to enact intangible mental boundaries that we draw between categories. Gary, for example, demonstrated this practice: “When I think of space together, I think of our time together. That's the way I look at it or envision it." Keith defined space through time, as well: "We have our own space as a couple, we set aside something, like we have times when we get to talk, or chat, and that's pretty much our time."
Some respondents emphasized it even more that space together did not involve a specific location, only time spent together. Anthony was one of them:

I'd say our own space comes with, really, our own time together, wherever that may be ... It's very dynamic, not a fixed location. It's a time period when we both have exclusively each other's time. I define that as our space.

A woman in another couple, Julianna, expressed a similar sentiment: "Whenever we're together, that's our space together. That's the time we spend together. We don't need a location ... It doesn't matter where we are as long as we are together." Space together was associated with or even considered tantamount to time together.

\section{Conclusions}

As long-distance couples define their relationship in interaction with each other and symbolically and linguistically draw a mental fence around it, they reinforce what a relationship means for them. They engage in boundary placement, separating singlehood and couplehood, and sometimes also putting a line between long-distance and close-distance relationships. However, they also transcend any real or perceived boundaries between distance and closeness by establishing and stressing their couplehood despite physical distances or even never having met. They can reinterpret, redefine, and extend the meanings of a relationship, intimacy, togetherness, and belonging.

Some of the couples faced legitimacy struggles concerning their LDR when their own definition of the relationship clashed with the opinions of family and friends who questioned their relationship. While such a situation usually created some tension, the critiques could not make my interviewees doubt their own definition of the relationship. Instead, they did their best to expand the definitions of those disapproving of what a valid, intimate, and "normal" relationship was.

Relationships tend to be placed in a temporal and spatial context-couples are frequently defined as people who are "together." Long-distance partners stretch such temporal and spatial limitations and demonstrate how togetherness and belonging can be achieved in novel, creative ways and in possibly unconventional spaces. As cyberspace and cognitive, socio-mental spaces are arguably less structured and more infinite than most physical spaces, people in these spaces might have even more agency to shape these spaces and more opportunities for limitless social interactions than they do in physical spaces. Behavioral norms might not be as rigid in cyberspace and socio-mental spaces (at least not yet) as they are in most physical spaces. Therefore, such spaces might provide more freedom and individualism for their inhabitants than physical spaces in general. At the same time, they can help bridge any real or perceived gaps between distance and closeness and generate a feeling of togetherness and belonging despite physical distances. With the creation of such spaces through modern communication technologies, long-distance couples of today possibly have better tools than long-distance partners of the past to assuage feelings of separateness. Long-distance couples that connect in cognitive, socio-mental spaces can also provide guidelines for redefining what space is, what its significance might be, and how it can be shaped and utilized.

My participants also often equaled their space together with time together. This suggests that time is still mostly omnipresent in our lives, but space has become more elusive, less relevant, and more open to redefinition and reshaping. Future studies could use the example of LDRs, but go beyond them and apply the results of this study to other situations and other types of social interactions to explore how intimacy (or the opposite, emotional distance) can be created or redefined by expanding its meanings and freeing it from any potential limitations of socio-temporal and spatial conventions. 
Brekhus, Wayne. 1996. “Social Marking and the Mental Coloring of Identity: Sexual Identity Construction and Maintenance in the United States." Sociological Forum 11:497-522.

Chayko, Mary. 2002. Connecting: How We Form Social Bonds and Communities in the Internet Age. Albany, NY: State University of New York Press.

Chayko, Mary. 2008. Portable Communities: The Social Dynamics of Online and Mobile Connectedness. Albany, NY: State University of New York Press.

Dainton, Marianne and Brooks Aylor. 2001. “A Relational Uncertainty Analysis of Jealousy, Trust, and Maintenance in Long-Distance Versus Geographically Close Relationships." Communication Quarterly 49(2):172-188.

Draucker, Claire B. et al. 2007. "Theoretical Sampling and Category Development in Grounded Theory." Qualitative Health Research 17:1137-1148.

Gerstel, Naomi and Harriet Gross. 1984. Commuter Marriage: A Study of Work and Family. New York: The Guilford Press.

Glaser, Barney G. 1978. Theoretical Sensitivity: Advances in the Methodology of Grounded Theory. New York: Sociology Press.

Guest, Greg, Arwen Bunce, and Laura Johnson. 2006. "How Many Interviews Are Enough? An Experiment With Data Saturation and Variability." Field Methods 18:59-82.

Guldner, Gregory T. 1996. “Long-Distance Romantic Relationships: Prevalence and Separation-Related Symptoms in College Students." Journal of College Student Development 37:289-296.

Guldner, Gregory T. and Clifford H. Swensen. 1995. “Time Spent Together and Relationship Quality: Long-Distance Relationships as a Test Case." Journal of Social and Personal Relationships 13:313-320.

Hill, Susan et al. 2009. "Comparing Intimacy Levels of Long-Distance and Geographically Close Dating Relation- ships." Paper presented at the annual meeting of the American Sociological Association, August 08, San Francisco, U.S.A.

Johnson, Amy et al. 2007. “College Students' Use of Email to Maintain Long-Distance and Geographically Close Interpersonal Relationships." Paper presented at the annual meeting of the International Communication Association, May 23, San Francisco, U.S.A.

Johnson, Amy et al. 2008. “College Students' Use of Relational Management Strategies in Email in Long-Distance and Geographically Close Relationships." Journal of Computer-Mediated Communication 13:381-404.

Knox, David E.etal. 2002. “Absence Makes the Heart Grow Fonder? Long-Distance Dating Relationships Among College Students." College Student Journal 36(3). Retrieved March 16, 2011 (http://findarticles.com/p/articles/mi_m0FCR/is_3_36/ai_95356586/.

LaRossa, Ralph. 2005. "Grounded Theory Methods and Qualitative Family Research." Journal of Marriage and Family 67:837-857

Lyndon, John, Tamarha Pierce, and Shannon O'Regan. 1997 "Coping With Moral Commitment to Long-Distance Dating Relationships." Journal of Personality and Social Psychology 73(1):104-113.

Maguire, Katheryn C. 2007. “'Will It Ever End?': A (Re)Examination of Uncertainty in College Student Long-Distance Dating Relationships." Communication Quarterly 55(4):415-432.

Maguire, Katheryn C. and Terry A. Kinney. 2010. “When Distance is Problematic: Communication, Coping, and Relational Satisfaction in Female College Students' Long-Distance Dating Relationships." Journal of Applied Communication Research 38:27-46.

Malterud, Kirsti. 2001. "Qualitative Research: Standards, Challenges, and Guidelines." The Lancet 358:483-488.

Nippert-Eng, Christena E. 1996. Home and Work: Negotiating Boundaries Through Everyday Life. Chicago: University of Chicago Press.
Richardson, Laurel. 1988. "Secrecy and Status: The Social Construction of Forbidden Relationships." American Sociological Review 53:209-219.

Sahlstein, Erin M. 2004. “Relating at a Distance: Negotiating Being Together and Being Apart in Long-Distance Relationships." Journal of Social and Personal Relationships 21:689-710.

Stafford, Laura. 2005. Maintaining Long-Distance and Cross-Residential Relationships. Mahwah, NJ: Lawrence Erlbaum Associates.

Stafford, Laura and Andy J. Merolla. 2007. "Idealization, Reunions, and Stability in Long-Distance Dating Relationships." Journal of Social and Personal Relationships 24:37-54.

Strauss, Anselm L. 1987. Qualitative Analysis for Social Scientists. Cambridge: Cambridge University Press.
Vaughan, Diane. 1986. Uncoupling: Turning Points in Intimate Relationships. New York: Oxford University Press.

Winfield, Fairlee E. 1985. Commuter Marriage: Living Together, Apart. New York: Columbia University Press.

Zerubavel, Eviatar. 1979. Patterns of Time in Hospital Life. Chicago: University of Chicago Press.

Zerubavel, Eviatar. 1981. Hidden Rhythms: Schedules and Calendars in Social Life. Chicago: University of Chicago Press.

Zerubavel, Eviatar. 1991. The Fine Line: Making Distinctions in Everyday Life. New York: Free Press.

Zerubavel, Eviatar. 1996. “Lumping and Splitting: Notes on Social Classification." Sociological Forum 11:421-433. 